\title{
Effects of Chemical Reactions on the Properties of Copolyesters Made from Poly(ethylene terephthalate) Prepolymer and Liquid Crystalline Polymer
}

\author{
Chang Ik Hwang and O Ok PARK* \\ Department of Chemical Engineering, Korea Advanced Institute of Science \& Technology, \\ 373-1 Kusung-Dong, Yusung-ku, Taejon 305-701, Korea
}

(Received July 11, 1994)

\begin{abstract}
Copolyesters were prepared by melt-phase polycondensation of poly(ethylene terephthalate) (PET) prepolymer and a thermotropic liquid crystalline polymer (LCP), $60 \mathrm{~mol} \%$ $p$-hydroxybenzoic acid and $40 \mathrm{~mol} \%$ poly(ethylene terephthalate) (PHB60/PET40). The copolyesters were characterized using gel permeation chromatography (GPC), nuclear magnetic resonance (NMR), thermal analysis, and wide angle X-ray diffraction measurement. The molecular weights of final copolyesters decreased with the addition of LCP. GPC results indicate that chain scission reaction of LCP occurs accompanied by chain-growing reaction of PET. From NMR analysis, LCP added underwent transesterification resulting in statistical reorganization of chain sequence with producing ether type by-products responsible for limiting the chain growth of copolyesters. It was observed that the crystallization of PET was delayed and melting temperature decreased with increasing LCP content in copolyesters. The resulting thermal properties and structural regularities of copolyester can be modified by exchange reactions during preparation.
\end{abstract}

KEY WORDS Liquid Crystalline Polymers / Poly(ethylene terephthalate) /

Exchange Reaction / Molecular Weight / Ether / Crystallization / Melting

Temperature Depression /

In the last two decades, the increasing demand for high modulus and high strength materials has drawn considerable interest to the field of liquid crystalline polymers (LCPs). A variety of thermotropic LCPs has been developed; one of the first known thermotropic LCPs is the copolyester of $p$-hydroxybenzoic acid (PHB) and poly(ethylene terephthalate) (PET) disclosed by Jackson and Kuhfuss. ${ }^{1}$ Blending PHB/PET copolyester with other various polyesters represents an interesting procedure for application and fundamental studies of the properties of LCP/polymer blends. $^{2-5}$ Studies on the blends of this LCP with PET have been conducted in various research groups. The crystallization rates of PET in the blends were higher than that of pure PET, which was attributed to nucleation of PET by LCP. ${ }^{6-9}$ The phase behavior and miscibility of LCP/PET blends have also been reported by several workers. ${ }^{10-13}$ Phase separation via spinodal decomposition was observed for the blend prepared by solution blending. ${ }^{10}$ Blending of polymers is thought to be an effective means for improving properties of one or more components. However, in general, when a rigid rod polymer and a flexible polymer are simply mixed together, one would expect them to be immiscible in the first place.

Reactive blending may provide a useful way to improve physical properties during the preparation of new polymeric materials from already existing polymers. The potential utilization of reactions between components of

* To whom all correspondence should be addressed. 
polyester blend has been found of interest. Friedrich and coworkers ${ }^{11}$ reported that annealing the LCP/PET blend in the melt caused transesterification reactions that resulted in depression of melting temperature of the PET by $42^{\circ} \mathrm{C}$. Lee and Dibenedetto ${ }^{14}$ suggested that chemical reactions could be used to improve the adhesion between aromatic fibers and thermoplastic matrix. The reactive blending is particularly suitable for polycondensates due to the presence of many reactive groups along the polymer chains.

The ultimate goal of this study is to show the possibility of modification of the properties of PET by the addition of LCP by understanding the mechanism of chemical reactions which may be inevitable for potential application. In this preliminary study, copolyesters made from LCP and low molecular weight of PET were prepared and characterized. The effects of chemical reactions on resulting thermal property and structural regularity are discussed.

\section{EXPERIMENTAL}

The polymers used in this work were liquid crystalline polymer and PET prepolymer. LCP consists of a $60 \mathrm{~mol} \% \mathrm{PHB}$ and $40 \mathrm{~mol} \% \mathrm{PET}$, obtained from Mitsubishi Kasei. Its intrinsic viscosity was $0.69 \mathrm{dlg}^{-1}$. PET prepolymer having a degree of polymerization less than 10 $\left(\bar{M}_{n}=1180, \bar{M}_{w}=3220\right)$ was supplied from an industrial source. All materials were dried in a vacuum oven at $100^{\circ} \mathrm{C}$ for $12 \mathrm{~h}$ to minimize moisture effects before use.

Several copolyesters with varying compositions of LCP were prepared by the melt-phase polycondensation of PET prepolymer and LCP. All copolymerizations were conducted in a cylindrical flask equipped with a vacuum distillation head, stainless steel agitator, and condensate trap. A typical run started from charging total weight of $140 \mathrm{~g}$ of PET prepolymer and LCP to the reactor. When the temperature of the mixture reached to $270^{\circ} \mathrm{C}$, the agitator was engaged and vacuum applied for $60 \mathrm{~min}$. The temperature was raised to $280^{\circ} \mathrm{C}$ and the vacuum was maintained at 0.18 Torr for $3 \mathrm{~h}$.

Intrinsic viscosities of the polyesters were measured in a $60 / 40$ phenol/tetrachloroethane solution with a concentration of $0.5 \mathrm{~g} / 100 \mathrm{ml}$ at $30^{\circ} \mathrm{C}$. Molecular weight and distribution were obtained by gel permeation chromatography (GPC). GPC measurements were carried out using a Waters $150 \mathrm{C}$ provided with three $\mu$-stragel columns connected in series with porosity of $10^{3}, 10^{4}, 10^{5} \AA$ and $\mathrm{OCP} / \mathrm{CHCl}_{3}$ $(1: 4)$ was used as the eluent at $35^{\circ} \mathrm{C}$. Calorimetric measurements were performed to evaluate thermal transitions of polymers in a Du Pont DSC 910. All samples were scanned from $30^{\circ} \mathrm{C}$ to $300^{\circ} \mathrm{C}$ at a heating rate of $10^{\circ} \mathrm{C} \mathrm{min}^{-1}$. After scanning, the samples were quickly quenched to room temperature and reheated using the same conditions. Wide angle $\mathrm{X}$-ray diffraction studies were carried on a Rigaku X-ray generator. The specimens were made by compression molding for $5 \mathrm{~min}$ at $270^{\circ} \mathrm{C}$, quenched with liquid nitrogen, and crystallized isothermally for $20 \mathrm{~min}$ at $190^{\circ} \mathrm{C}$. The $2 \theta$ axis was scanned from $5^{\circ}$ to $35^{\circ}$ at a rate of $4 \mathrm{deg} \min ^{-1}$ in steps of 0.1 . NMR measurements were carried out using a Bruker AMX FT NMR spectrometer operating at a resonance frequency of $500 \mathrm{MHz}$ for protons.

\section{RESULTS AND DISCUSSION}

\section{Gel Permeation Chromatography}

PET and four samples of copolyesters with different compositions were prepared as listed in Table I and Figure 1 shows their GPC curves. The average molecular weight of final copolyesters decreased with increasing LCP. Judging from the initial molecular weight distribution of pure LCP, it can be seen that chain cleavage reaction of LCP occurs with chain-growing reactions of PET. Transreaction also occurs simultaneously and competitively with the polymerization of PET. It is 


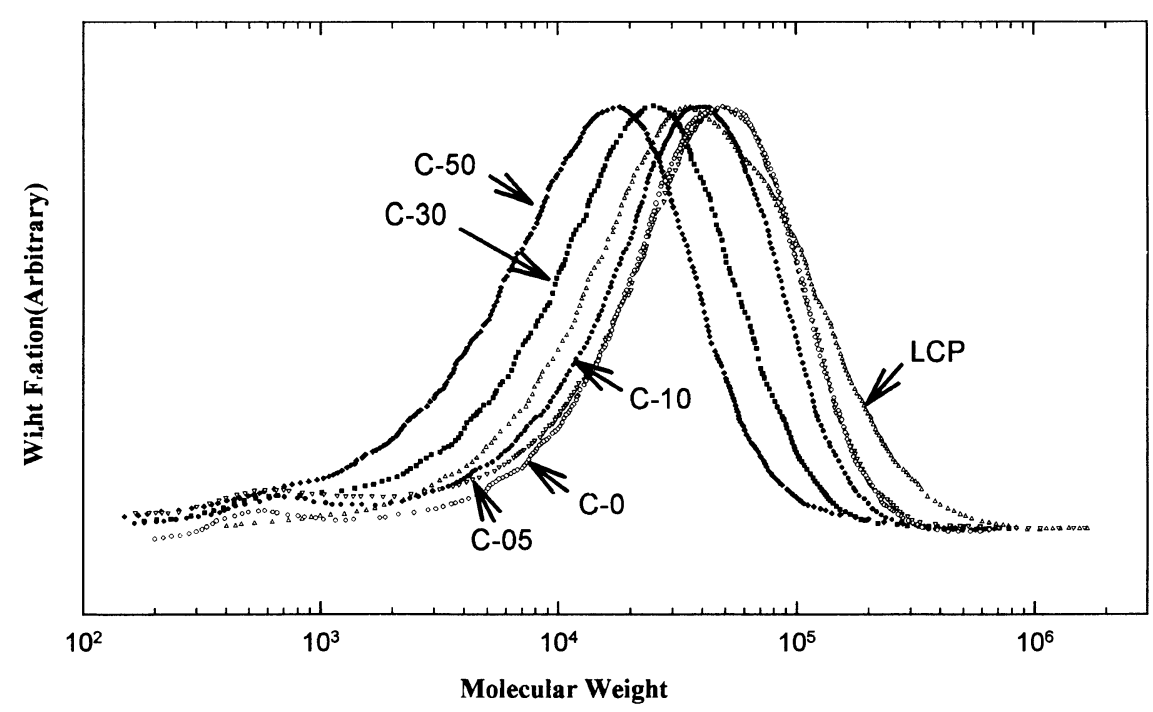

Figure 1. GPC curves of polyesters prepared with different compositions; $\mathrm{O}, \mathrm{PET} ; \nabla, \mathrm{C}-05 ; \mathbf{C}, \mathrm{C}-10$; 口, C-30; $\diamond$, C-50; $\triangle$, pure LCP.

Table I. Molecular weights and distribution of polyesters

\begin{tabular}{cccccc}
\hline \multirow{2}{*}{$\begin{array}{c}\text { Designa- } \\
\text { tion }\end{array}$} & $\begin{array}{c}\text { LCP } \\
\text { content }\end{array}$ & $\begin{array}{c}\bar{M}_{n} \\
\left(\times 10^{4}\right)\end{array}$ & $\begin{array}{c}\bar{M}_{w} \\
\left(\times 10^{4}\right)\end{array}$ & $\bar{M}_{w} / \bar{M}_{n}$ & $\mathrm{I.V}^{\mathrm{b}}$ \\
\cline { 2 - 5 } & \multicolumn{1}{c}{$\mathrm{dlg}^{-1}$} \\
\hline $\mathrm{C}-0^{\mathrm{a}}$ & 0 & 2.61 & 5.84 & 2.24 & 0.63 \\
$\mathrm{C}-05$ & 5 & 2.52 & 5.65 & 2.24 & 0.62 \\
$\mathrm{C}-10$ & 10 & 1.92 & 4.33 & 2.26 & 0.55 \\
$\mathrm{C}-30$ & 30 & 1.45 & 3.22 & 2.25 & 0.46 \\
$\mathrm{C}-50$ & 50 & 0.66 & 2.33 & 3.58 & 0.32 \\
\hline
\end{tabular}

${ }^{a}$ Poly(ethylene terephthalate) (PET). ${ }^{\mathrm{b}}$ Intrinsic viscosity, measured in a $60 / 40 \mathrm{phenol} /$ tetrachloroethane solution with $0.5 \mathrm{~g} / 100 \mathrm{ml}$ at $30^{\circ} \mathrm{C}$.

likely that the molecular weight of copolyesters strongly depends on LCP composition.

\section{NMR Study and Reaction}

To examine more closely the mechanism of molecular weight change of copolyesters prepared, NMR spectra of the copolyesters were compared with those of as-received LCP. The proton NMR spectrum of pure LCP in trifluoroacetic acid is shown in Figure 2. Resonance assignment follows from the litera-

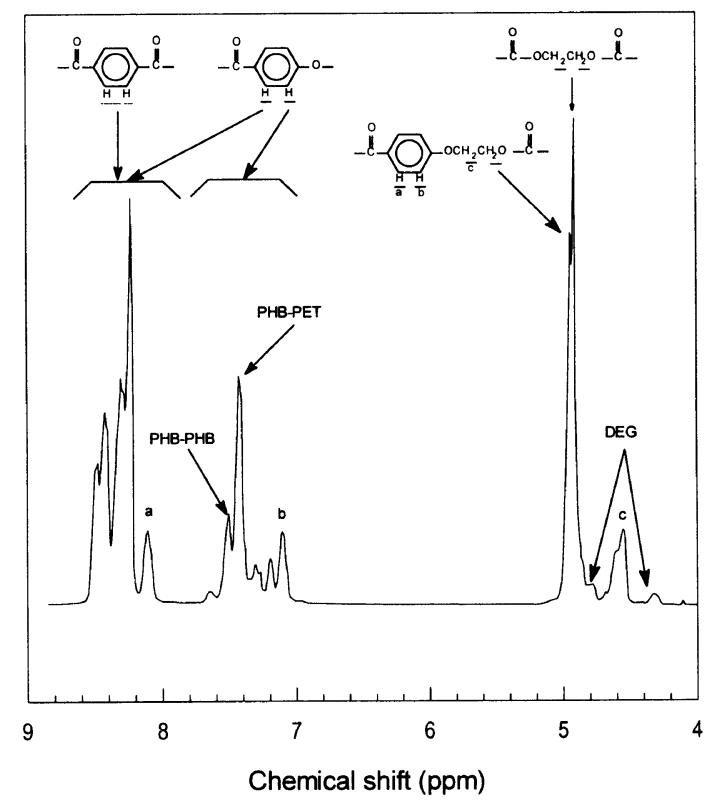

Figure 2. Proton NMR spectrum of pure LCP in trifluoroacetic acid.

ture. $^{15-17}$ Three unassigned peaks at 7.17, 7.26, and $7.30 \mathrm{ppm}$ in the pure LCP correspond to the protons of the aromatic group under different chemical environments or sequences 
such as chemical inhomogenuity in the synthesis of this copolyester. The spectra of copolyesters prepared had similar absorption peaks, indicating that the resultant copolymers may have exactly the same types of functional groups as the as-received pure LCP, including ethylene glycol, terephthalic acid, hydroxybenzoic acid, and ether. However, the relative amounts of absorption peaks changed, especially in the region of $\delta=7-7.8$. Figure 3 illustrates a comparison of the proton NMR spectra of C-05, C-30, C-50, and pure LCP and Table II summarizes the relative intensity changes in absorption. Nicely et al. studied the sequence distribution of copolyesters based upon PET and PHB by NMR spectroscopy. ${ }^{15}$ The spectra of these types provide a direct measure of a PHB repeat unit bonded to another PHB or a PET unit. Table II shows that the peak of PHB-PET bond relative to that of PHB-PHB bond significantly increases from the initial ratio of 2.8 for as-received LCP, irrespective of initial feed compositions. This indicates all copolyesters underwent transesterification resulting in randomization of chain sequence during the preparation of the copolyesters. The peaks at $7.08 \mathrm{ppm}$ and $7.42 \mathrm{ppm}$ increased while peak at $7.52 \mathrm{ppm}$ decreased for each copolyester. It is sure that ether type unit is generated during the preparation of copolyesters since there would be no change in relative intensity ratio of these three unit if there is no chemical reaction. As shown in the third column in Table II, the relative peak intensity of the aromatic proton of the ether unit at $7.08 \mathrm{ppm}$ to that of PHB-PHB bond plus PHB-PET bond decreases with increase in LCP. The copolyester with $5 \mathrm{wt} \%$ of LCP shows the largest ratio of ether unit to PHB-PHB plus PHB-PET units indicating the most frequent transesterification reaction between PET and LCP phase. The PHB unit in a LCP molecule certainly has more probability of exchange reaction with other molecules of PET or LCP when LCP content is relatively small. Moreover, the fraction of ether peak

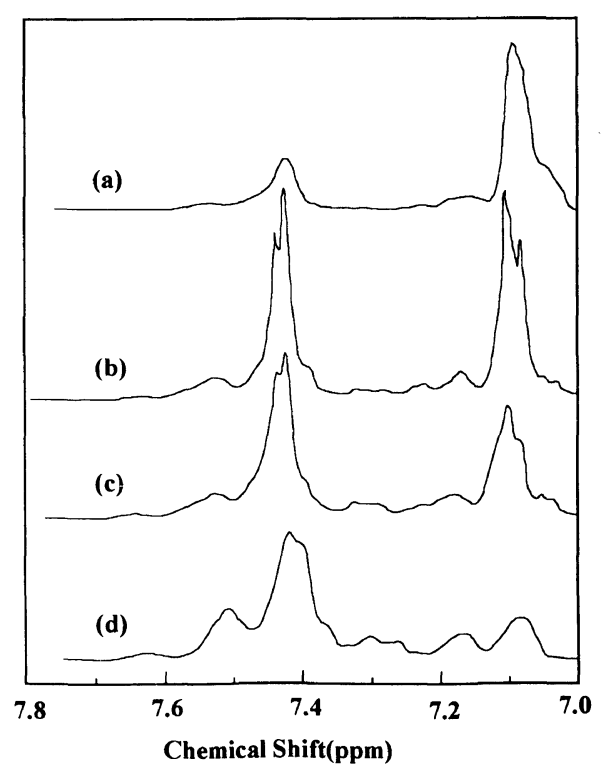

Figure 3. Proton NMR spectra of copolyesters of (a) C-05, (b) C-30, (c) C-50, and (d) pure LCP in the region of $\delta=7-7.8 \mathrm{ppm}$.

Table II. Summary of relative intensity changes in absorption from proton NMR spectra

\begin{tabular}{|c|c|c|c|c|c|}
\hline \multirow{2}{*}{ Copolyester } & \multirow{2}{*}{ PHB-PHB ${ }^{\mathrm{a}}:$ PHB-PET ${ }^{\mathrm{b}}:$ Ether $^{\mathrm{c}}$} & Ether & \multirow{2}{*}{$\frac{\text { Ether }}{\mathrm{A}^{\mathrm{d}}}$} & \multirow{2}{*}{$\frac{\mathbf{B}^{\mathbf{e}}}{\mathbf{A}}$} & \multirow{2}{*}{$\frac{\text { Ether }}{E G^{\mathrm{f}}}$} \\
\hline & & PHB-PHB + PHB-PET & & & \\
\hline C-05 & $1: 5: 13$ & 2.2 & 0.63 & 0.09 & 0.012 \\
\hline $\mathrm{C}-10$ & $1: 4.1: 7.6$ & 1.5 & 0.54 & 0.10 & 0.023 \\
\hline C-30 & $1: 4.5: 6.1$ & 1.1 & 0.46 & 0.13 & 0.038 \\
\hline C-50 & $1: 3.9: 3.2$ & 0.65 & 0.33 & 0.16 & 0.079 \\
\hline LCP & $1: 2.8: 0.8$ & 0.21 & 0.14 & 0.19 & 0.12 \\
\hline
\end{tabular}

a,b,c, and ${ }^{\mathrm{f}}$ Chemical shift at 7.52, 7.42, 7.08, and $4.92 \mathrm{ppm}$, respectively. ${ }^{\mathrm{d}}$ Total intensity of all peaks in the region of $\delta=7-7.8$. ${ }^{\mathrm{e}}$ Sum of intensities of unassigned three peaks at 7.17, 7.26, and $7.30 \mathrm{ppm}$. 
intensity at $7.08 \mathrm{ppm}$ to total intensity of all peaks in the region of $\delta=7-7.8$ exhibits higher values for copolyesters with lower LCP content as shown in fourth column in Table II. The fifth column in Table II shows that the fraction of the sum of unassigned three peaks at $7.17,7.26$, and $7.30 \mathrm{ppm}$ to the total intensity of all peaks in the region of $\delta=7-7.8$ exhibits lower values for copolyesters with lower LCP content. This is due to dilution of the PHB molar concentration for copolyesters with lower LCP content. From the relatively low contribution of these unassigned peaks as shown in Figure 3 and Table II, we may ignore the effects of these unassigned peaks compared with the peak of interest exhibiting significant change at 7.08, 7.42, and $7.52 \mathrm{ppm}$. Considering the ether content relative to EG from last

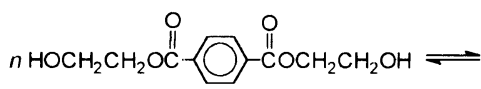

be built up by the formation of ester linkages through ester exchange reactions with LCP.

During the alcoholysis reaction of PET with LCP, a phenolic group is generated.

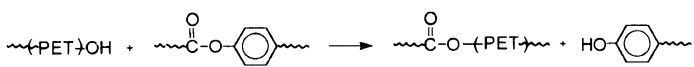

This liberated phenolic group attacks ester linkages via two competing mechanisms. The following reaction scheme between PET and the phenolic group may be assumed. A similar phenolysis reaction can be applied to LCP chains.

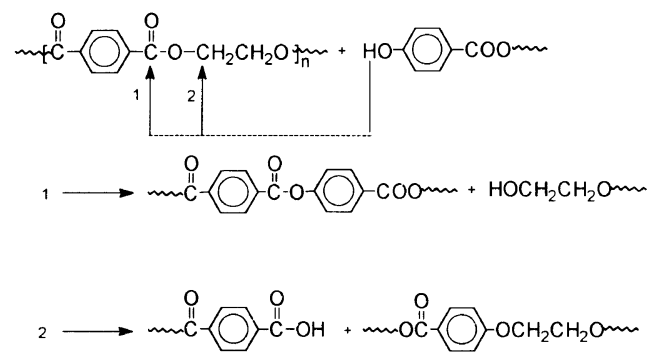

column in Table II, high concentration of ether is observed for copolyesters with higher LCP fraction. This is due to the ether residue in pure LCP in addition to ether from the exchange reactions.

In the presence of low LCP content, most of PET prepolymers are polymerized to yield high molecular weight copolyesters. However, with higher LCP content, it is more difficult to obtain high molecular weight copolyesters. Therefore, it is obvious that molecular chain growth of PET in the presence of high LCP content is influenced by the ether type byproducts.

The PET chain grows due to polycondensation by alcoholysis, forming the polyester to liberate a molecule of diol for each step of chain growth. The molecular chain of PET can also

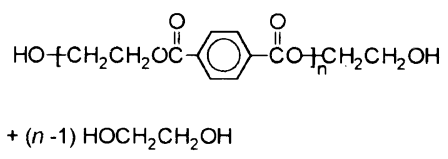

First, the phenolic group attack carbonyl carbon atoms of Scheme 1 to yield new esters with different chain lengths and sequences. This contributes to the build-up of PET chains. On the other hand, if the phenolic group attacks the methylenic carbon of Scheme 2, it produces ether type product incorporating $p$-ethyleneoxybenzoate units and acid end groups with elimination of alcohol groups, consequently limiting the molecular weight increase in PET. Therefore, with higher LCP content, the concentration of the highly reactive phenolic group increases which consequently leads to more limitation of chain growth reaction of PET. That is, as the amount of LCP increases, more LCP molecules may take part in exchange reaction between $L C P$ and a series of different chain lengths of PET or LCP and much more ether type by-products might be produced along with relatively low chain growth of copolyesters.

When polymerizations are carried out at 
high temperature, chain-scission reactions may compete with chain-growing reactions and become one of the most important limiting factors for increase in molecular weight. Other side reactions, leading to spurious moieties in the chains or to unwanted by-products in the final polymer, can take place along with exchange reactions.

\section{Thermal Studies}

Figure 4 shows DSC thermograms of samples and Table III summarizes the characteristics. Pure PET shows a distinct crystallization exotherm followed by a melting endotherm. LCP exhibits a glass transition around $86^{\circ} \mathrm{C}$ and broad endotherm due to the fusion of crystallites between $170^{\circ} \mathrm{C}$ and $250^{\circ} \mathrm{C}$. As the amount of LCP increases, glass transition temperature and exothermic peak shift to high temperature. Figure 5 shows $T_{\mathrm{c}, \mathrm{p}}$ and $T_{\mathrm{m}}$ of copolyesters as a function of LCP content. The higher exothermic peak temperature with increasing LCP suggests that the crystallization of PET is delayed in copolyesters with high addition of LCP. Since PET is capable of crystallizing during quenching immediately after the first heating scan, $\Delta H_{\mathrm{m}}-\Delta H_{\mathrm{c}}$ corresponds to the PET fraction crystallized. The

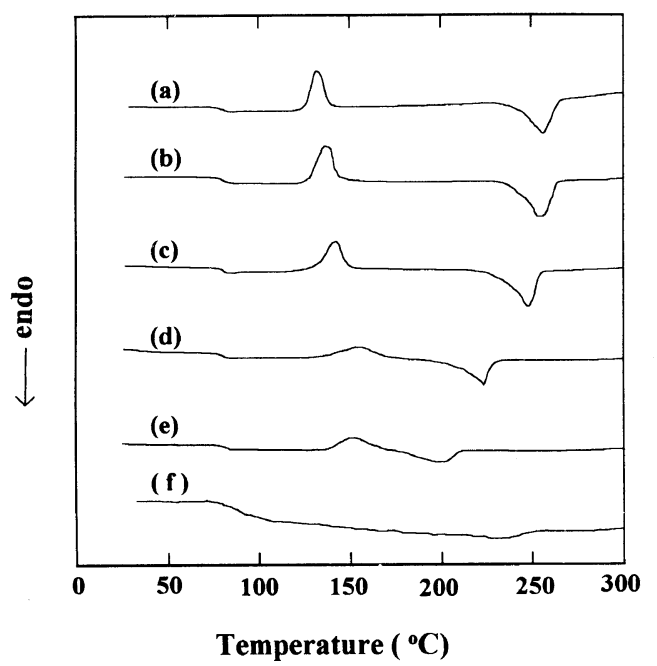

Figure 4. DSC thermograms of (a) PET and copolyesters of (b) C-05, (c) C-10, (d) C-30, (e) C-50, and (f) LCP. values decrease in copolyesters with higher LCP content. That is, the crystallization of PET during quenching is more hindered with increase in LCP content. The hindered crystallization behavior in copolyesters with high LCP content indicates that transesterification occurs between PET and LCP during the preparation. That is, the delayed crystallization behavior in copolyesters with higher LCP content indicates that the chemical sequence of PET is more modified into an irregular structure by the incorporation of different types of chemical units. Moreover, the LCP copolyester rearranges into another copolymer with changed sequence, possibly resulting in some

Table III. Characteristics of thermal transition from DSC thermograms

\begin{tabular}{|c|c|c|c|c|c|c|}
\hline \multirow{2}{*}{ Samples } & $T_{\mathrm{g}}^{\mathrm{a}}$ & $T_{\mathrm{c}, \mathrm{p}}^{\mathrm{b}}$ & $\Delta H_{\mathrm{c}}^{\mathrm{c}}$ & $T_{\mathrm{m}}^{\mathrm{d}}$ & $\Delta H_{\mathrm{m}}^{\mathrm{e}}$ & $\Delta H_{\mathrm{m}}-\Delta H_{\mathrm{c}}$ \\
\hline & ${ }^{\circ} \mathrm{C}$ & ${ }^{\circ} \mathrm{C}$ & $\mathbf{J ~ g ~}^{-1}$ & ${ }^{\circ} \mathrm{C}$ & $\mathrm{Jg}^{-1}$ & $\mathbf{J ~ g ~}^{-1}$ \\
\hline C-0 & 79.6 & 132.3 & 41.0 & 256.6 & 54.6 & 13.6 \\
\hline C-05 & 79.8 & 135.5 & 37.7 & 251.6 & 51.6 & 13.9 \\
\hline C-10 & 79.8 & 144.5 & 39.6 & 245.7 & 45.0 & 5.4 \\
\hline C-30 & 81.3 & 154.0 & 31.0 & 220.8 & 32.5 & 1.5 \\
\hline C-50 & 82.6 & 151.4 & 20.0 & 199.6 & 20.1 & 0 \\
\hline
\end{tabular}

${ }^{a}$ Glass transition temperature. ${ }^{\mathrm{b}}$ Crystallization peak temperature. ${ }^{\mathrm{c}}$ Heat of crystallization. ${ }^{\mathrm{d}}$ Peak temperature of melting endotherm. ${ }^{\mathrm{e}}$ Heat of fusion.

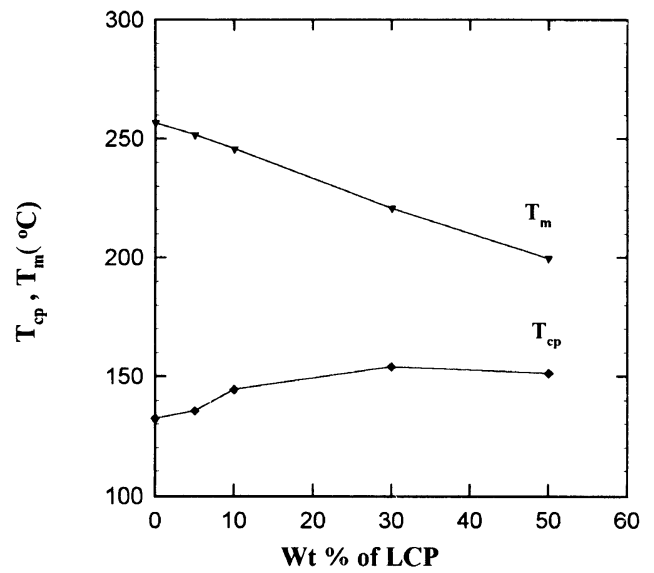

Figure 5. Plots of melting peak temperature $\left(T_{\mathrm{m}}\right)$ and crystallization peak temperature $\left(T_{\mathrm{c}, \mathrm{p}}\right)$ of copolyesters as a function of LCP content. 
loss of liquid crystallinity by the transesterification reaction. Therefore, the more hindered crystallization of copolyesters with increasing LCP content is directly related to the extent of transesterification. The nucleation effect of LCP in the physical blend of LCP/PET ${ }^{6-9}$ was not observed in these transesterified copolyesters.

More pronounced effects are observable on the melting behavior of PET. As shown in Figure 5, melting temperature depression is noticeable with increasing LCP content. This is consistent with the previous reports ${ }^{9}$ showing that a transesterification occurs, especially for blends with high LCP content. The presence of diethylene glycol (DEG), even in low concentration $(1-2 \mathrm{wt} \%)$, in polyesters decreases polymer crystallinity, resulting in lowered melting temperatures. ${ }^{18}$ But in our case, the DEG content for all copolyesters have same order of magnitude of $2 \%$ relative to EG concentration from the peak area in NMR spectra, so that it can be concluded that melting temperature depression and hindered crystallization are due to the reduction of structural regularity owing to randomization effects of exchange reactions. This is the cause for decrease in $\Delta H_{\mathrm{m}}, \Delta H_{\mathrm{c}}$, and $T_{\mathrm{m}}$.

\section{WAXD Studies}

Wide angle $\mathrm{X}$-ray diffraction patterns of several polyesters crystallized isothermally for $20 \mathrm{~min}$ at $190^{\circ} \mathrm{C}$ are shown in Figure 6. PET reflections can be seen at $2 \theta$ of $16.3^{\circ}, 17.7^{\circ}$, $21.6^{\circ}, 22.8^{\circ}, 26^{\circ}, 28.0^{\circ}$, and $32.5^{\circ}$. Highly crystallized PET is resolved into easily identifiable crystalline peaks. PET reflection at $28^{\circ}$ is less intense in the patterns of the other copolyesters. The diffraction pattern of the crystalline phase of all copolyesters exhibits almost the same reflections of the PET component except that of C-50 samples. The C-50 sample does not exhibit a crystalline peak because isothermal crystallization temperature of $190^{\circ} \mathrm{C}$ corresponds to the melting region as shown in Figure 4 and the diffraction pattern

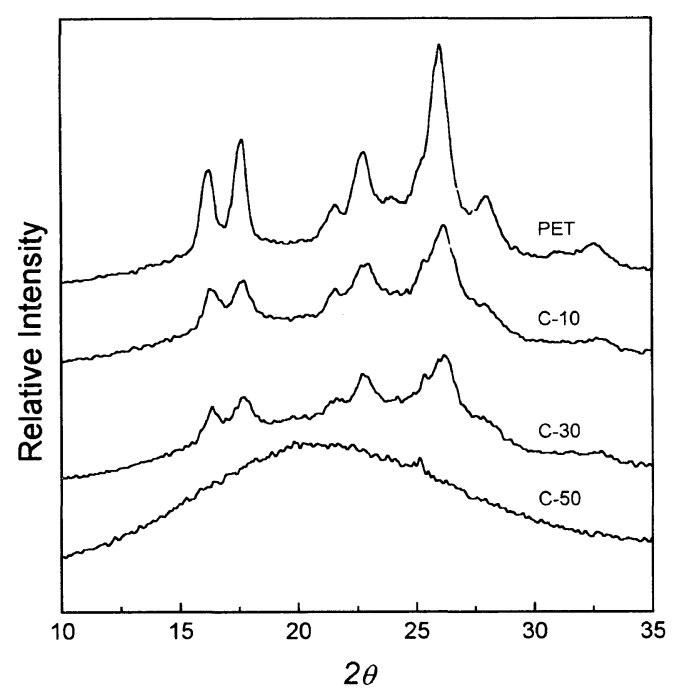

Figure 6. WAXD spectra of polyesters crystallized for $20 \mathrm{~min}$ at $190^{\circ} \mathrm{C}$.

of $\mathrm{C}-50$ represents the quenched amorphous melt at $190^{\circ} \mathrm{C}$. When the $\mathrm{C}-50$ sample is isothermally crystallized at $145^{\circ} \mathrm{C}$ for $10 \mathrm{~min}$, its diffraction resembles that of the PET component indicating that the crystalline phase in the C-50 sample adopts the lattice structure of PET (not presented here). These patterns point qualitatively to lower overall crystallinity and decreasing crystalline order for samples with increasing LCP content due to transesterification during preparation. There seems no apparent lattice structure change in the crystalline phase in the copolyesters from Figure 6. However, it is likely that packing is more imperfect in copolyesters with higher LCP content considering crystal distortion due to the incorporation of different chemical sequences into the PET chain.

The level of crystallinity that can be attained at a given crystallization temperature depends on the molecular weight and structural regularity of the chain. In case of homopolymers that crystallized under isothermal crystallization conditions, the level of crystallinity is relatively high at lower molecular weight. However, in these copolyesters, the level of crystallinity obtained decreases with decreas- 
ing molecular weight. This indicates that the level of crystallinity is dominantly affected by the introduction of irregular structural units into the PET chain.

\section{CONCLUSIONS}

During the preparation of copolyesters, LCP added underwent chain scission and transesterification resulting in statistical recombination of chain sequences. With higher LCP content, the concentration of the highly reactive phenolic group increases which subsequently leads to limitation of chain growth of copolyesters. From the thermal behaviors of copolyesters, melting temperature depression and hindered crystallization are more significant in copolyester with increasing LCP content owing to the lowered structural regularity. The addition of varying LCP content to the PET prepolymer during copolymerization significantly affects thermal properties and structural regularity due to exchange reactions.

Acknowledgments. Part of the financial support was from MOST of Korea, to which authors are very grateful.

\section{REFERENCES}

1. W. J. Jackson, Jr. and H. F. Kuhfuss, J. Polym. Sci., Polym. Chem. Ed., 14, 2043 (1976).

2. J.-F. Croteau and G. V. J. Laivins, J. Appl. Polym. Sci., 39, 2377 (1990).

3. A. Zaldua, G. Munoz, J. J. Pena, and A. Santamaria, Polymer, 32, 782 (1991).

4. S. H. Jung and S. C. Kim, Polym. J., 20, 73 (1988).

5. T. Kyu and P. Zhuang, Polym. Commun., 29, 99 (1988).

6. S. K. Bhattacharya, A. Tendokar, and A. Misra, Mol. Cryst. Liq. Cryst., 153, 501 (1987).

7. S. K. Sharma, A. Tendokar, and A. Misra, Mol. Cryst. Liq. Cryst., 157, 597 (1988).

8. E. G. Joseph, G. L. Wilkes, and D. G. Baird, "Polymer Liquid Crystals," A. Blumstein, Ed., Plenum Press, New York, N.Y., 1984.

9. E. G. Joseph, G. L. Wilkes, and D. G. Baird, Am. Chem. Soc., Div. Polym. Chem., Polym. Prepr., 24, 304 (1983).

10. A. Nakai, T. Shimaku, H. Hasigawa, and T. Hasimoto, Macromolecules, 19, 3008 (1986).

11. K. Friedrich, M. Hess, and R. Kosfeld, Makromol. Chem., Macromol. Symp., 16, 251 (1988).

12. C. U. Ko, G. L. Wilkes, and C. J. Wong, J. Appl. Polym. Sci., 37, 3063 (1989).

13. P. Zhuang, T. Kyu, and J. L. White, Polym. Eng. Sci., 28, 1093 (1988).

14. W.-C. Lee and A. T. Dibenedetto, Polym. Eng. Sci., 32, 400 (1992).

15. V. A. Nicely, J. T. Dougherty, and L. W. Renfro, Macromolecules, 20, 573 (1987).

16. R. W. Lenz, J. I. Jin, Kurt A. Feichtinger, Polymer, 24, 2377 (1983).

17. F. Yamamoto, Y. Shuto, and K. Yoshimura, JP 60-186527 (1985) (to Mitsubishi Kasei Co.).

18. J.-M. Besnoin and K. Y. Choi, JMS.-Rev. Macromol. Chem. Phys., C29(1), 55 (1989). 